\title{
Chinese Medicine NeuroAiD Efficacy Stroke Recovery - Extension Study (CHIMES-E Study): An Observational Multicenter Study to Investigate the Longer-Term Efficacy of NeuroAiD in Stroke Recovery
}

\author{
N. Venketasubramanian ${ }^{a, c}$ Sherry Young ${ }^{d}$ San San Tay $^{d}$ Hui Meng Chang ${ }^{\mathrm{e}}$ \\ T. Umapathi ${ }^{f}$ Bernard Chan ${ }^{a}$ Asita de Silva ${ }^{\text {h }}$ Lawrence Wong $^{i}$ Jose Navarroj \\ Yu-Dong Zhao ${ }^{g}$ Say Beng Tan ${ }^{9}$ Christopher Chen ${ }^{\text {b }}$

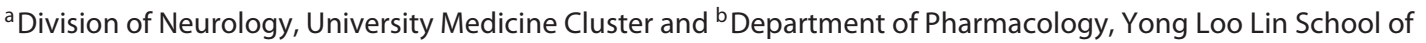 \\ Medicine, National University of Singapore, ' Neuroscience Clinic, Raffles Hospital, ${ }^{\mathrm{d}}$ Department of Rehabilitation \\ Medicine, Changi General Hospital, e Department of Neurology, National Neuroscience Institute - Singapore \\ General Hospital Campus, ${ }^{\mathrm{f}}$ Department of Neurology, National Neuroscience Institute - Tan Tock Seng Hospital \\ Campus, and ${ }^{9}$ Singapore Clinical Research Institute, Singapore, Singapore; ${ }^{\mathrm{h}}$ Clinical Trials Unit, Department of \\ Pharmacology, Faculty of Medicine, University of Kelaniya, Kelaniya, Sri Lanka; 'Division of Neurology, Prince of \\ Wales Hospital, Chinese University of Hong Kong, Hong Kong, SAR, China; 'Stroke Unit, San Vicente Ward, \\ University of Santo Tomas Hospital, Manila, Philippines
}

\section{Key Words}

Stroke · Recovery $\cdot$ NeuroAiD $\cdot$ Traditional Chinese medicine

\begin{abstract}
Background: Stroke carries a poor long-term prognosis for death and disability. There are few acute treatments that reduce death and disability after stroke. The ongoing international, multicenter, randomized, placebo-controlled, double-blind CHIMES trial is currently testing the hypothesis that a 3-month course of the traditional Chinese medicine MLC601 (NeuroAiD) is superior to placebo in reducing neurological deficit and improving functional outcome after acute ischemic stroke in patients receiving standard stroke care. This extension study tests the hypothesis that at 2 years, an initial 3-month administration of NeuroAiD is superior to placebo in reducing neurological deficit and improving functional outcome in patients with cerebral infarction
\end{abstract}

\begin{tabular}{ll}
\hline KARGER & $\begin{array}{l}\text { (c) 2013 S. Karger AG, Basel } \\
\text { 1015-9770/13/0357-0018 } \$ 38.00 / 0\end{array}$ \\
$\begin{array}{l}\text { E-Mail karger@karger.com } \\
\text { www.karger.com/ced }\end{array}$ & $\begin{array}{l}\text { This is an Open Access article licensed under the terms of } \\
\text { the Creative Commons Attribution-NonCommercial-No- } \\
\text { Derivs 3.0 License (www.karger.com/OA-license), applica- } \\
\text { ble to the online version of the article only. Distribution for } \\
\text { non-commercial purposes only. }\end{array}$
\end{tabular}

of an intermediate range of severity. Methods: Study subjects will be those who are already participants in CHIMES aged above 21 years, had signs and symptoms of acute stroke, $6 \leq \mathrm{NIHSS} \leq 14$, neuroimaging consistent with ischemic stroke, and received study medication within $72 \mathrm{~h}$ of stroke onset. A subject will not be eligible for inclusion in CHIMES-E if they have withdrawn consent from all participation and follow-up for CHIMES. Subjects will be contacted at $6,12,18$ and 24 months after CHIMES enrolment. After verbal consent is obtained, subjects will be assessed for functional state by the modified Rankin scale (mRS) and Barthel Index $(\mathrm{BI})$, and a history of recurrent vascular events as well as medical events. The primary outcome measure will be the mRS at month 24 . Secondary outcome measures will be $\mathrm{mRS}$ and $\mathrm{BI}$ at 6, 12 and 18 months, and $\mathrm{BI}$ at 24 months. Analysis will be based on the intention-to-treat principle. If the number of patients lost to follow-up is substantial, a sensitivity analysis based on the last observation carried forward method will

Narayanaswami Venketasubramanian

Division of Neurology, University Medicine Cluster, Yong Loo Lin School of Medicine National University Health System, National University of Singapore

1E Kent Ridge Road, NUHS Tower Block Level 10, Singapore 119228 (Singapore)

E-Mail drnvramani@gmail.com 
be carried out, to compare the results with those from the main analysis without imputation. Based on a cumulative odds ratio of 1.5 for the NeuroAiD group, a two-sided test of $5 \%$ type I error and an expected 30\% dropout rate after 2 years of follow-up for the 1,100 patients recruited into CHIMES, the 770 subjects with mRS data expected to be available at year 2 yields an $89 \%$ power to detect a difference in efficacy between NeuroAiD and placebo. Conclusions: This study will provide evidence for the longer-term efficacy of an initial course of a neurorestorative therapy after acute ischemic stroke of intermediate severity.

Copyright $\odot 2013$ S. Karger AG, Basel

\section{Introduction}

Stroke is a major cause of death and disability in many countries of the world with a dismal long-term prognosis. One-year mortality after stroke is $33 \%$; $37 \%$ of the survivors remain dependent [1]. At 5 years after stroke, survival is approximately $40 \%$, with about half of survivors being disabled and dependent [2]. In a recent large multicenter clinical trial of stroke patients with a third of participants coming from Asia, at a median follow-up of 4 years, $19-22 \%$ were disabled and $12-14 \%$ were dependent, requiring regular help with everyday activities [3]. With the aging of Asian as well as global populations, the number of disabled stroke survivors is likely to rise.

There are few acute treatments that reduce death and disability after stroke. Organized inpatient care for stroke patients reduces death, disability and institutionalization at 1 year, with beneficial effects that are sustained for even up to 10 years [4]. Intravenous thrombolysis within $3 \mathrm{~h}$ and up to $4.5 \mathrm{~h}$ of acute ischemic stroke onset reduces disability at 3 months without increasing mortality $[5,6]$, with continued benefit at 1 year [7]. However, not all hospitals have geographical stroke units; few patients receive thrombolytic therapy for various reasons $[8,9]$. Alternative strategies using neuroprotectants have failed to live up to their earlier promise [10]. Clearly, better treatments are needed to enhance recovery after stroke.

There are conflicting results of the effect of pharmacological interventions later after stroke to enhance recovery [11]. The recently published FLAME trial showed the benefit at 3 months of fluoxetine combined with physiotherapy among patients with ischemic stroke and motor deficits [12]. However, the largest evidence base is for amphetamines [13]. Animal experiments show that amphetamines promote axonal sprouting into deafferentated subcortical areas from contralesional projection neurons
[14] as well as neurite growth followed by synaptogenesis in the neocortex [15]. Clinical trials have shown no evidence at present to support the use of amphetamine after stroke; but there was a trend towards improved motor function [16]. Moreover, a 5-week trial of amphetamine in aphasia showed benefit at 6 months [17]. Another trial showed benefit in motor recovery at 1 and 12 months after drug discontinuation [18]. These data suggest that the beneficial effects of pharmacological interventions may occur or be maintained after the drug has been stopped. It is entirely possible that the apparent 'lack' of efficacy of neurorestorative interventions thus far may not just be due to small sample sizes or varying severity of study subjects, but rather to premature summative assessment, and that an assessment at an extended time frame might show positive effects.

Traditional medicine is widely used throughout Asia after stroke [19]. Previous clinical studies performed in China have shown that MLC601 (NeuroAiD), a traditional Chinese medicine (TCM), increases recovery from neurological disability and functional outcome in stroke patients and thus may be beneficial in poststroke rehabilitation [20-23]. It has no adverse effects on hematological or biochemical parameters [23-25]. NeuroAiD combines 9 herbal components and 5 animal components. It is manufactured by Shitian Pharmaceutical in Tianjin (certified as GMP compliant by Sino-FDA) and was registered with the Sino-FDA in August 2001 for the treatment of stroke recovery. While its exact mechanism of action is not known, it has been shown to increase cerebral blood flow after stroke, which may assist in recovery [26]. It appears to induce neurogenesis in rodent and human cells, promote cell proliferation as well as neurite outgrowth, stimulate the development of a dense axonal and dendritic network, and activate $\mathrm{K}_{\mathrm{ATP}}$ channels [2729].

In the ongoing CHIMES study, an international, multicenter, randomized, double-blinded, parallel-group phase III trial with 1,100 subjects, the hypothesis being tested is that MLC601 (NeuroAiD), 4 capsules 3 times a day taken over a 3-month period, is superior to placebo in reducing neurological deficit and improving functional outcome after acute ischemic stroke in patients receiving standard stroke care [30]. An extension study of CHIMES provides a rare opportunity to study the longterm effects of a short course of a neurorestorative treatment. There are many potential trajectories thereafter over the longer term - if they have benefited, treated subjects may continue to improve, sustain an improvement or deteriorate; if harmed they may recover, maintain sta- 
Table 1. CHIMES-E measurement and evaluation schedule

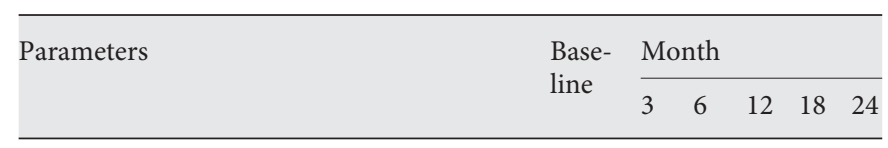

\begin{tabular}{|c|c|c|c|c|c|c|}
\hline Eligibility check & $\mathrm{x}$ & & $\mathrm{x}$ & & & \\
\hline Informed consent & $\mathrm{x}$ & & $\mathrm{x}$ & & & \\
\hline Demographic data & $\mathrm{x}$ & & & & & \\
\hline Vital signs & $\mathrm{x}$ & & & & & \\
\hline Time from stroke onset & $\mathrm{x}$ & & & & & \\
\hline Medical history & $\mathrm{x}$ & & & & & \\
\hline Physical examination & $\mathrm{x}$ & & & & & \\
\hline Neurological evaluation & $\mathrm{x}$ & & & & & \\
\hline Stroke history & $\mathrm{x}$ & $\mathrm{x}$ & $\mathrm{x}$ & $\mathrm{x}$ & $\mathrm{x}$ & 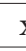 \\
\hline Risk factors & $\mathrm{x}$ & & & & & \\
\hline Previous medication & $\mathrm{x}$ & & & & & \\
\hline
\end{tabular}

Ongoing medication/change in

\begin{tabular}{lllllll}
\multicolumn{1}{c}{ concomitant medication } & $\mathrm{x}$ & $\mathrm{x}$ & & & \\
\hline CT scan/MRI brain & $\mathrm{x}$ & & & & & \\
\hline Laboratory examination & $\mathrm{x}$ & $\mathrm{x}$ & & & & \\
\hline NIHSS & $\mathrm{x}$ & $\mathrm{x}$ & & & & \\
\hline mRS & $\mathrm{x}$ & $\mathrm{x}$ & $\mathrm{x}$ & $\mathrm{x}$ & $\mathrm{x}$ & $\mathrm{x}$ \\
\hline BI & $\mathrm{x}$ & $\mathrm{x}$ & $\mathrm{x}$ & $\mathrm{x}$ & $\mathrm{x}$ & $\mathrm{x}$ \\
\hline MMSE & $\mathrm{x}$ & $\mathrm{x}$ & & & & \\
\hline Drug accountability and compliance & $\mathrm{x}$ & $\mathrm{x}$ & & & & \\
\hline Medical event & $\mathrm{x}$ & $\mathrm{x}$ & $\mathrm{x}$ & $\mathrm{x}$ & $\mathrm{x}$ & $\mathrm{x}$
\end{tabular}

tus quo or deteriorate further; if static they may show late recovery, continue their static state or deteriorate. Such information will be most helpful to better understand the chronic effects of short-term therapies.

CHIMES-E will test the hypothesis that NeuroAiD given over the initial 3 months is superior to placebo in reducing neurological deficit and improving functional outcome at 2 years in patients with cerebral infarction of an intermediate range of severity on the National Institutes of Health Stroke Scale (NIHSS).

\section{Methods}

\section{Study Design}

CHIMES-E is an observational study that will assess outcomes in subjects over the 21 months following their exit from CHIMES.

\section{Study Population Inclusion/Exclusion Criteria}

A subject will be eligible for inclusion in CHIMES-E if randomized into CHIMES - aged above 21 years, had signs and symptoms of acute stroke, $6 \leq$ NIHSS $\leq 14$, neuroimaging consistent with ischemic stroke, and received study medication within $72 \mathrm{~h}$ of stroke onset. A subject will not be eligible for inclusion in CHIMESE if they have withdrawn consent from all participation and follow-up for CHIMES.

\section{Baseline Data}

Baseline data obtained at entry into CHIMES will be used. These include:

- Demographic data: date of birth, gender, ethnicity

- Time from stroke onset

- Risk factors: previous myocardial infarction, angina, hypertension, peripheral vascular disease, diabetes mellitus, hyperlipidemia, smoking history, habitual drinking

- Stroke history: date of previous stroke, type of stroke

- Medical history: neurological, cardiovascular, endocrine, hematological, eyes, ear, nose, throat, peripheral vascular, respiratory, gastrointestinal, hepatic, renal, genitourinary, dermatological, musculoskeletal, neoplasia, immune, and psychiatric

- Vital signs: temperature, weight, height, blood pressure, pulse rate

- Physical examination: general appearance, neurological, eyes, head and neck, ear, nose throat, heart, lungs, abdomen, lymph nodes, genitourinary, extremities, skin, musculoskeletal, immune, and psychiatric

- NIHSS

- Prestroke modified Rankin score (mRS)

- Mini-Mental State Examination (MMSE)

- Previous and ongoing medications: name of drugs, route, dosage, frequency, date started, date stopped, indication

\section{Assessment Time Points}

Neurological recovery of the subjects will be assessed at:

- month 6 ( \pm 1 month)

- month 12 ( \pm 1 month)

- month 18 ( \pm 1 month)

- month 24 ( \pm 1 month)

\section{Assessments Performed}

Subjects will be contacted by telephone. After explaining the nature of the study using a standardized telephone script, verbal consent will be obtained prior to performing the assessments. The data will be recorded on a standardized case report form. The assessments include (table 1):

- mRS

- Barthel Index (BI)

- Self-report of having received rehabilitation

- Self-report of having received TCM

- Self-report of having suffered a new vascular event - stroke or myocardial infarction; or died - if so, the cause

- Self-report of developing other significant illnesses

\section{Study Endpoints}

The primary efficacy endpoint is the mRS grades at month 24 $( \pm 1$ month $)$

The secondary endpoint measures will be the functional recovery of the subjects as assessed by:

- mRS scale grades at month 6 ( \pm 1 month), month 12 ( \pm 1 month) and month 18 ( \pm 1 month)

- BI at month 6 ( \pm 1 month), month 12 ( \pm 1 month), month 18 ( \pm 1 month), and month 24 ( \pm 1 month). 
Concomitant Therapies

There are no planned therapeutic study interventions. All subjects will continue to receive medical and rehabilitative care in consultation with their physicians.

Premature Discontinuation

A subject may be withdrawn prematurely under the following circumstances:

- Withdraw consent

- Protocol violation

- If warranted for subject's best interest at the investigator's discretion

\section{Statistics and Outcome}

\section{Power Analysis}

We assume that $35 \%$ of moderately severe stroke patients will be dead ( $\mathrm{mRS}=6$ ) and $25 \%$ will be dependent, distributed among mRS $2-5$, at 2 years [1-3]. We expect an overall $30 \%$ dropout rate after 2 years of follow-up for the 1,100 patients recruited into CHIMES. Assuming 770 subjects with mRS data are available at year 2, a cumulative odds ratio of 1.5 for the NeuroAiD group and a twosided test of $5 \%$ type I error, the power of the study is approximately $89 \%$. Even with a sample size as low as 606 , we can ensure at least $80 \%$ power.

\section{Efficacy Analysis}

Analysis will be based on the intention-to-treat principle. If the number of patients lost to follow-up is substantial, a sensitivity analysis based on the last observation carried forward method will be carried out, to compare the results with those from the main analysis without imputation.

\section{Per Protocol and Subgroup Analysis}

Per protocol analysis will be performed for primary and secondary efficacy outcomes as described above.

Subgroup analysis will be performed for the following:

- Time from stroke onset: therapeutic window $\leq 24 \mathrm{~h}$ and therapeutic window $>24 \mathrm{~h}$

- NIHSS score: patients with $6 \leq$ NIHSS $\leq 10$ and patients with $10<$ NIHSS $\leq 14$.
- Type of cerebral infarction: patients presenting lacunar infarction and patients with large artery occlusive disease

- Antiplatelet treatment received

\section{Ethical Considerations}

\section{Ethics Approval}

In obtaining and documenting informed consent, the investigator should adhere to ICH GCP guideline E6 and to the ethical principles that have their origin in the Declaration of Helsinki.

Prior to the beginning of the study, the investigator should have approval/favorable opinion of the protocol from the Ethics Committee.

\section{Informed Consent}

Before any subject is included, verbal informed consent must be obtained from the subject or his/her legally acceptable representative. In obtaining and documenting informed consent, the investigator or coinvestigator should adhere to the principles as stipulated in ICH GCP guideline.

\section{Conclusions}

This study will provide evidence for the longer-term efficacy of an initial course of a neurorestorative therapy by TCM, specifically NeuroAiD, after acute ischemic stroke of intermediate severity. The novel study design of long-term assessments after initial short-course therapy should spur further evaluation of treatments previously thought to be unhelpful.

\section{Disclosure Statement}

N.V., S.Y., S.S.T., H.M.C., T.U., B.C., S.B.T. and C.C. received funding from the National Medical Research Council of Singapore, CHIMES Society and Moleac for NeuroAiD research. A. de S., L.W. and J.N. received funding from the CHIMES Society and Moleac for NeuroAiD research. Y.-D.Z. has no disclosures.

\section{References}

1 Appelros P, Nydevik I, Viitanen M: Poor outcome after first-ever stroke: predictors for death, dependency, and recurrent stroke within the first year. Stroke 2003;34:122-126.

2 Hankey GJ: Long-term outcome after ischaemic stroke/transient ischaemic attack. Cerebrovasc Dis 2003;16(suppl 1):14-19.
3 Fransen M, Anderson C, Chalmers J, Chapman N, Davis S, MacMahon S, Neal B, Sega R, Terent A, Tzourio C, Woodward M, PROGRESS: Effects of a perindopril-based blood pressure-lowering regimen on disability and dependency in 6,105 patients with cerebrovascular disease: a randomized controlled trial. Stroke 2003;34:2333-2338. 
4 Stroke Unit Trialists' Collaboration: Organised inpatient (stroke unit) care for stroke. Cochrane Database Syst Rev 2007:CD000197.

-5 National Institute of Neurological Disorders and Stroke rt-PA Study Group: Tissue plasminogen activator for the treatment of acute ischaemic stroke. New Engl J Med 1995;333: 1581-1587.

6 Hacke W, Kaste M, Bluhmki E, Brozman M, Dávalos A, Guidetti D, Larrue V, Lees KR, Medeghri Z, Machnig T, Schneider D, von Kummer R, Wahlgren N, Toni D, ECASS Investigators: Thrombolysis with alteplase 3 to $4.5 \mathrm{~h}$ after acute ischemic stroke. $\mathrm{N}$ Engl J Med 2008;359:1317-1329.

-7 Kwiatkowski TG, Libman RB, Frankel M, Tilley BC, Morgenstern LB, Lu M, Broderick JP, Lewandowski CA, Marler JR, Levine SR, Brott T: Effects of tissue plasminogen activator for acute ischemic stroke at one year. National Institute of Neurological Disorders and Stroke Recombinant Tissue Plasminogen Activator Stroke Study Group. N Engl J Med 1999;340:1781-1787.

-8 Mold F, Wolfe C, McKevitt C: Falling through the net of stroke care. Health Soc Care Community 2006;14:349-356.

-9 Eissa A, Krass I, Bajorek BV: Optimizing the management of acute ischaemic stroke: a review of the utilization of intravenous recombinant tissue plasminogen activator (tPA). J Clin Pharm Ther 2012;37:620-629.

$>10$ Ginsberg MD: Current status of neuroprotection for cerebral ischemia: synoptic overview. Stroke 2009; 40(suppl 3):S111-S114.

-11 Paolucci S, De Angelis D: New developments on drug treatment rehabilitation. Clin Exp Hypertens 2006;28:345-348.

12 Chollet F, Tardy J, Albucher JF, Thalamas C, Berard E, Lamy C, Bejot Y, Deltour S, Jaillard A, Niclot P, Guillon B, Moulin T, Marque P, Pariente J, Arnaud C, Loubinoux I: Fluoxetine for motor recovery after acute ischaemic stroke (FLAME): a randomised placebo-controlled trial. Lancet Neurol 2011;10:123-130.

13 Martinsson L, Eksborg S: Drugs for stroke recovery: the example of amphetamines. Drugs Aging 2004;21:67-79.
14 Ramic M, Emerick AJ, Bollnow MR, O’Brien TE, Tsai SY, Kartje GL: Axonal plasticity is associated with motor recovery following amphetamine treatment combined with rehabilitation after brain injury in the adult rat. Brain Res 2006;1111:176-186.

15 Stroemer RP, Kent TA, Hulsebosch CE: Enhanced neocortical neural sprouting, synaptogenesis, and behavioral recovery with $\mathrm{D}$ amphetamine therapy after neocortical infarction in rats. Stroke 1998;29:2381-2393.

16 Sprigg N, Bath PM: Speeding stroke recovery? A systematic review of amphetamine after stroke. J Neurol Sci 2009;285:3-9.

17 Walker-Batson D, Curtis S, Natarajan R, Ford J, Dronkers N, Salmeron E, Lai J, Unwin DH: A double-blind, placebo-controlled study of the use of amphetamine in the treatment of aphasia. Stroke 2001;32:2093-2098.

18 Walker-Batson D, Smith P, Curtis S, Unwin $\mathrm{H}$, Greenlee R: Amphetamine paired with physical therapy accelerates motor recovery after stroke. Further evidence. Stroke 1995;26: 2254-2259.

19 Pandian JD, Liu M, Misbach J, Venketasubramanian N: Alternative therapies for stroke treatment in Asia. Int J Stroke 2011;6:541543.

20 Chen C, Venketasubramanian N, Gan RN, Lambert C, Picard D, Chan BP, Chan E, Bousser MG, Xuemin S: Danqi Piantang Jiaonang (DJ), a traditional Chinese medicine, in poststroke recovery. Stroke 2009;40: 859-863.

-21 Siow CH: Neuroaid in stroke recovery. Eur Neurol 2008;60:264-266.

22 Kong KH, Wee SK, Ng CY, Chua K, Chan KF, Venketasubramanian N, Chen C: A doubleblind, placebo-controlled, randomized phase II pilot study to investigate the potential efficacy of the traditional Chinese medicine NeuroAiD (MLC 601) in enhancing recovery after stroke (TIERS). Cerebrovasc Dis 2009;28: 514-521.

23 Harandi AA, Abolfazli R, Hatemian A, Ghragozlee K, Ghaffar-Pour M, Karimi M, Shahbegi S, Pakdaman H, Tabasi M, Tabatabae AL, Nourian A: Safety and Efficacy of MLC601 in Iranian patients after stroke: a double-blind, placebo-controlled clinical trial. Stroke Res Treat 2011;2011:721613.
24 Gan R, Lambert C, Lianting J, Chan ES, Venketasubramanian N, Chen C, Chan BP, Samama MM, Bousser MG: Danqi Piantan Jiaonang does not modify hemostasis, hematology, and biochemistry in normal subjects and stroke patients. Cerebrovasc Dis 2008;25: 450-456.

25 Young SH, Zhao Y, Koh A, Singh R, Chan BP, Chang HM, Venketasubramanian N, Chen C; CHIMES Investigators. Safety profile of MLC601 (Neuroaid) in acute ischemic stroke patients: a Singaporean substudy of the Chinese Medicine Neuroaid Efficacy on Stroke recovery study. Cerebrovasc Dis 2010;30:1-6.

26 Bavarsad Shahripour R, Shamsaei G, Pakdaman H, Majdinasab N, Nejad EM, Sajedi SA, Norouzi M, Hemmati A, Manouchehri RH, Shiravi A: The effect of NeuroAiD ${ }^{\mathrm{TM}}$ (MLC601) on cerebral blood flow velocity in subjects' post-brain infarct in the middle cerebral artery territory. Eur J Intern Med 2011; 22:509-513.

27 Heurteaux C, Gandin C, Borsotto M, Widmann C, Brau F, Lhuillier M, Onteniente B, Lazdunski M: Neuroprotective and neuroproliferative activities of NeuroAid (MLC601, MLC901), a Chinese medicine, in vitro and in vivo. Neuropharmacology 2010; 58:987-1001.

28 Quintard H, Borsotto M, Veyssiere J, Gandin C, Labbal F, Widmann C, Lazdunski M, Heurteaux C: MLC901, a traditional Chinese medicine protects the brain against global ischemia. Neuropharmacology 2011;61:6226231.

29 Moha Ou Maati H, Borsotto M, Chatelain F, Widmann C, Lazdunski M, Heurteaux C: Activation of ATP-sensitive potassium channels as an element of the neuroprotective effects of the Traditional Chinese Medicine MLC901 against oxygen glucose deprivation. Neuropharmacology 2012;63:692-700.

30 Venketasubramanian N, Chen CL, Gan RN, Chan BP, Chang HM, Tan SB, Picard D, Navarro JC, Baroque AC 2nd, Poungvarin N, Donnan GA, Bousser MG, CHIMES Investigators: A double-blind, placebo-controlled, randomized, multicenter study to investigate Chinese Medicine Neuroaid Efficacy on Stroke recovery (CHIMES Study). Int J Stroke 2009;4:54-60. 